\title{
Curriculum design for primary care physicians
}

\section{Oliver Samuel}

The Pinn Medical Centre, Pinner, Middlesex, UK

\section{Introduction}

A curriculum is a complex entity. Stenhouse ${ }^{1}$ wrote that 'a curriculum is an attempt to communicate the essential principles and features of an educational proposal in such a form that it is open to critical scrutiny and capable of effective translation into practice.' In thinking about the development of education for general practice, it is necessary to consider a range of practical learning activities and to discuss how they fit together to contribute to the diverse range of knowledge and skills needed by a modern general practitioner.

The educational aims for general practice training can be described broadly under five headings. The most important will always be to promote the high quality of patient care. Next it is essential to facilitate professional development and to equip the doctor with the ability to continue to learn new skills relevant to the developing requirements of general practice throughout his career. It is essential to encourage intellectual integrity and professional curiosity. Doctors need to remain alert and stimulated through many years of hard work and the challenge is to provide an educational climate that will contribute to the prevention of 'burn-out'. Finally attention must be given to encourage professional survival despite the stress of modern medical practice in a changing climate of political and economic difficulties.

Medical students have always been required to memorize vast amounts of factual information, even though much of this information goes rapidly out of date. In their early clinical training, doctors need to concentrate on acquiring practical skills in dealing with patients, in performing medical procedures, in management and in many other spheres. Experienced doctors have to go on learning throughout their careers to stay in touch with medical progress.

It is important to consider some educational premises before planning the content and methods

Correspondence: O. Samuel, F.R.C.G.P.

This article is based on a paper presented at the Winter Meeting of the National Association of Clinical Tutors held on 27 November 1992. to be included within the curriculum. Knowles ${ }^{2}$ has described some of the principles of adult learning. He suggests that adults desire and enact a tendency towards self-directedness although, at times, they may be very dependent on others. Adults' experiences are a rich resource for learning. They learn more effectively through experiential techniques of education such as discussion or problem solving. Adults are sensitive to their specific learning needs generated by real life tasks or problems. Adult education programmes, he suggests, should be based around 'life application' categories and sequenced according to learners' readiness to learn. Finally he observes that adults are competencybased learners in that they wish to apply newly based skills and knowledge to their immediate circumstances. Adults are, therefore, performance centred in their orientation to learning.

\section{How doctors learn}

These general observations about adult learning must be translated into the specifically medical situation. ${ }^{3}$ Clearly doctors need to develop a strong sense of professional autonomy. In clinical work, patients depend on their professional advisers to take their problems seriously and to base medical advice and treatment on an understanding of what is available and what would be the best course of action to be followed. In their continuing education, doctors have to feel fully responsible for their duty to continue to study and for choosing what and how to serve their own learning needs. It is still an unfortunate anomaly that many medical students are taught in a passive way and that their early professional experience in hospital, both as students and junior graduates that they have to fit into the bottom of rigidly hierarchical systems. Both these experiences inhibit independent thinking.

Doctors learn best what they perceive to be useful. They need opportunities to explore their daily work and discover the gaps. They also need to know of new developments that might become 
useful in their work. The curriculum must make space for rethinking ordinary work as well as exploring the frontiers of progress. Most doctors will learn more from an audit of their own work than from hearing about recent advances elsewhere in medicine. Doctors study in many different ways and different people have different preferred styles of learning. ${ }^{4}$ Some enjoy reading at home, others like attending meetings. All learn a great deal from modelling on the professional behaviour of senior colleagues (although it is a little unfashionable now to recommend such old-style methods of apprenticeship). Groups of colleagues meeting to share experiences and ideas can be a powerful way of modifying even the most deeply entrenched attitudes. An effective postgraduate education system can only cater for all members of the medical community by providing a range of diverse educational activities.

\section{Undergraduate education}

About half the graduates from British medical schools make their careers in general practice. Yet it has been a recent phenomenon for this popular discipline to be found significant time within the undergraduate curriculum. This paper makes no attempt to analyse this initial phase of the training of future general practitioners, but merely notes that many undergraduate schools have found it extremely difficult to introduce changes to their archaic curricula.

\section{Vocational training}

After graduation and completing the mandatory preregistration jobs, doctors who choose to make a career in general practice must complete 3 years of vocational training. Curiously, two of these are spent in hospital posts and only 1 year is taken as a trainee assistant in general practice. Almost half the availab!e training posts are in linked 3-year vocational training schemes that provide a training programme for at least half a day each week to complement the clinical work.

\section{(a) Remedial care}

Three are three overlapping phases to training of young doctors who emerge from hospital to work in primary care. The first is concerned with remedial care. All too many keen, altruistic, highly motivated students find it traumatic to have to struggle to be allowed on the wards of their teaching hospitals to work with patients. Many students are still being hurt by exposure to the utterly inappropriate experience of teaching by humiliation. Some senior doctors who may have neither time nor patience to help yet another group of students are still nominally responsible but too often absent from teaching rounds. The instruction available to preregistration housemen is notor- iously inadequate ${ }^{5}$ and the whole experience produces young doctors who are dispirited or detachedo from their patients' problems and unable to invest음 their clinical work with the enthusiasm with which $\frac{\bar{s}}{7}$ they started their studies.

Medical students are usually taught clinical methods that are quite different from those used by experienced doctors. ${ }^{6}$ Having first been made to. memorize innumerable facts they are usually $\overrightarrow{\vec{\omega}}$ taught to take clinical histories and perform $\stackrel{ }{\circ}$ examinations that are prolonged and comprehensive, ritualistic and unrelated to real clinical medi- 3 . cine. They graduate egg-bound with information 8 but ill-equipped to process it; overburdened with $\infty$ facts but in desperate need of worldly understand- $\vec{A}$ ing.

One of the early aims of vocational training is to restore the trainees' humanity and allow them to음 express and then make use of their feelings. They have to know that professional remoteness is defensive and usually misplaced, and that it is often completely appropriate to feel upset when they care $\stackrel{\rho}{?}$ for ill or distressed people.

\section{(b) Competency training}

The crux of training is to ensure that every trainee is clinically safe. It is impossible to encompass all medical knowledge or to be skilled in every $\frac{}{\mathbb{D}}$ available procedure. What is required is a decent $\varrho$ range of basic craft skills and a real understanding $\overrightarrow{\overline{0}}$ of personal limits. Knowing how to use colleagues and understanding their ability is one part of the art of practice. Most of the work of a general practice trainee is with patients who come with a bewildering assortment of problems. Some are straightforward medical matters and call on normal clinical 3 skills. The trainer supervises the work and ensures that ears are properly examined, electrocardio- $\frac{O}{3}$ grams are interpreted sensibly, emotionally distressed patients are suitably listened to and managed with empathy. Patients also come with $\frac{7}{0}$ social problems: poverty, unemployment, drug addiction and others and each demands a different $N$ range of responses, often involving other members $N$ of the primary health care team, social services or $\mathrm{N}$ secondary health services. Competence in pre- $\omega$ ventive health care, practice management, communication skills must all be assessed, and tuition and practical experience be provided when needed. $\stackrel{\Phi}{\mathscr{D}}$

Doctors have to be competent in the basic skill of + working across the range of problems that come daily to the surgery. Some expertise has permanent $\mathbb{D}$ value, regardless of the way clinical practice 
changes. This includes being able to listen properly to the patient and communicate appropriately; being able to examine the patient physically and to plan the patient's care. This all requires careful and regular assessment of the doctor's learning needs and attainments. The essence of one-to-one teaching involves regular evaluation and appropriate readjustment of the learning opportunities. The Joint Committee for Postgraduate Training for General Practice now requires formative assessment to be incorporated in all training posts.

\section{(c) Preparing for lift-off}

The major challenge of vocational training is to prepare each trainee for a demanding career and to equip him to stay intellectually alert. He has to learn how to continue to learn throughout his professional life and how to keep his professional curiosity alive. It is not enough just to establish that a doctor is safe to practice. He must be able to continue his professional and personal growth long after he has reached economic and professional maturity. Autonomy is essential provided it brings with it a sense of self-direction.

To balance devotion to the care of patients and a work ethic that will sustain his intellectual curiosity, the trainee has to learn to develop a sense of proportion. Patients will always take a high priority, but there are other demands on his time. Sometimes everything has to stop while a real emergency - chest pain, perhaps - is dealt with. Some patients demand immediate attention because they are vocal while others have greater needs but cannot enunciate them. The doctor has to sort this out. Every doctor needs outside interests and a balance must be struck between professional and personal needs. There are no easy solutions to working under pressure while surviving the stresses and rewards of a full family life. Learning how to cope is what vocational training is truly about.

The methods used in vocational training are firmly based on the principles of promoting the autonomy of the learner. The trainee takes an active and, as nearly as possible, equal role within the training practice, seeing patients and attending all practice activities including those concerned with management. The patients who attend the surgery provide a range of clinical and social problems to fuel the education furnace. The trainee takes on as much clinical responsibility as feels comfortable. Supervision of the work is regular and constructive and help is available at all times. Once a week, he joins with other trainees for a regular meeting to study specific topics and to share experiences. Most courses offer regular small groups work to study cases and problems, and this can provide an opportunity to reconsider the particular experience of each trainee in the context of a critical and supportive peer group. The key to the curriculum lies in regular assessment to help the trainee determine for himself what he needs to study. This important work is the duty of the trainer often helped by the vocational training scheme course organiser.

\section{Continuing medical education - the early phase}

\section{(a) Young principals' groups}

Once established in a practice, the educational needs of a general practitioner changes. The next struggle is to become competent within the setting of an established practice and with older doctors who may not work or think in the same way as their new colleague. At first there is a great deal of practical information to be learnt about the practice and the local facilities. Many young practitioners find that they miss the supportive companionship of the vocational training scheme and feel somewhat isolated in their new role. To fill this gap, a network of young practitioner groups has grown up around the country. ${ }^{7}$ These groups are all autonomous and many appear at first to serve a largely social and supportive function. Some do undertake formal academic activities but usually without calling on outsiders for help. Their persistent presence all over the country suggests that they serve a positive need.

\section{(b) Higher professional education courses}

Some doctors decide that they wish to follow a rather more academic approach to extending their training, but do not wish to undertake the rigors of working for a postgraduate degree. A small number of Faculties of the Royal College of General Practitioners and university departments have developed Higher Professional Training courses. ${ }^{8}$ These are aimed at doctors within the early years in general practice. They run for 1 or 2 years and offer a range of academic experiences. Most arrange for semi-structured visits to inspect each other at work. ${ }^{9}$ All work within a small group context and with encouragement for the course members to play a large part in planning and running the programme.

Another suggestion that is currently being canvassed for the interests of those who seek formal academic recognition of their educational endeavours concerns developing projects of portfoliolearning. In this scheme, each learner is responsible both for choosing what to study and for developing a portfolio of evidence of his achievements. 


\section{(c) M.Sc. in General Practice}

Within the last 5 years, several university departments of general practice have developed courses leading to a postgraduate degree. Most are parttime but require a commitment of at least 2 days a week for 2 or 3 years. These courses offer training in scientific method and require participants to undertake research as part of their evaluation.

\section{Continuing medical education - the rest of time}

The continuing learning needs of all general practitioners are served in very many ways. Most doctors receive several journals and reading is still an important but sometimes forgotten source of further information. The limited benefits of peripatetic attendance at postgraduate meetings (be they at local hospitals or fashionable ski resorts) have recently been overemphasized by the Department of Health's requirement for general practitioners to accumulate 'brownie points' to become entitled to the Postgraduate Education Allowance. Fortunately there are other useful educational resources available for those with more eclectic tastes.

Within the range of activities described here, there is only a small place for 'experts'. Clearly a great deal can be gained from a seminar that is resourced by a knowledgeable person, for doctors who need to learn about a particular topic. There is no place for lecturers to show slides in the dark after lunch, pouring their wisdom onto a passive and often disinterested audience. Graduates undoubtedly learn best by active participation in finding out about what they themselves have identified as a subject about which they need to know. The best place for experts is, therefore, in helping doctors discover what their needs are and in tutoring them in their own educational endeavours; helping them learn for themselves. The intention of those who plan postgraduate studies should be to provide a range of alternatives. The principles to be followed are to involve the participants in course planning and to offer opportunities both for practical experience and critical reflection.

The routine place of quality assurance in current medical practice has yet to be fully accepted, but the idea of engaging in the regular critical review of current professional work is well appreciated and an excellent one. At present medical audit remains largely an educational exercise. ${ }^{10}$ Most doctors still need to learn how to gather and analyse data about their present performance. Clearly general practitioners have much to gain from sharing in studies of patients with the same condition and many Medical Audit Advisory Groups now organize such events. Shared studies between primary and secondary care are becoming more established and $\varrho$ eventually it is to be hoped that all these activities will become part of the routine management of the $\stackrel{?}{C}$

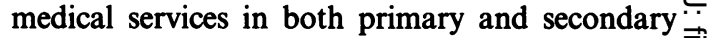
care. At present medical audit provides a valuable $\stackrel{\vec{S}}{\stackrel{F}{.}}$ focus for educational activities in general practice. $\overrightarrow{0}$

Small groups that meet regularly to share prob- 듬 lems have been accepted for many years as being an $\overline{\bar{c}}$. effective way of reviewing clinical work. ${ }^{11}$ They are $\mathbb{\Omega}$ powerfully effective in enabling doctors to reconsider their established attitudes to many aspects of ${ }^{\infty}$ their work. The scope of groups to offer mutual $\vec{\circ}$ support has been mentioned earlier. Not all estab- $\overrightarrow{\vec{\omega}}$ lished general practitioners are comfortable in such $\stackrel{\omega}{\sigma}$ a milieu, but the generation of doctors who have $\overline{8}$ experienced group work as part of vocational 3 training will find value in joining an on-going group for specific study purposes. ${ }^{12}$ There is an ${ }_{\infty}^{\circ}$ important difference between a small group meet- $\overrightarrow{+}$ ing for mutual support and one that meets to examine current clinical problems or to study 0 particular topics. This type of group will work very 을 much more effectively (and safely) if it is facilitated by an experienced and skilled group leader. ${ }^{13} \longrightarrow$ Providing such leadership can be an entirely appropriate application of educational funding.

There has recently been increased interest $\overrightarrow{0}$ practice-based learning activities. All members 0 the primary care team need to learn to wo together. Audit is often shared between all the professionals, doctors, nurses, health visitors and others while the administrative staff provide help with data handling. Until recently the pharma- $\frac{\circ}{\circ}$

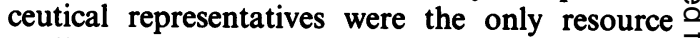
available to practices needing to mount their own $\overrightarrow{\overrightarrow{0}}$ training, but this usually meant watching a video related in some way to the company's products. Under the stress of the recent health service reorganization, many practices have decided to examine their own learning needs and to make time available for staff to take a close look at their work and what they require to improve it. Similarly, local groups of practices who share a common interest the same computer system perhaps - frequently now arrange to meet in each others surgeries to share their ideas.

Postgraduate study in general practice has many locations and there should be something available $\widetilde{N}$ locally to interest everyone. The postgraduate $N$ centres will probably continue to serve as a com- $N$ mon meeting ground for many, but the location of many centres may not be convenient for everyone. Undoubtedly the academic needs of general practitioners must be catered for in a whole variety of ways and, if this really works, the whole community will benefit from keeping general practice intellectually alive despite the trying times in which we work and live. 


\section{References}

1. Stenhouse, L. An Introduction to Curriculum Research and Development. Heinemann Educational, London, 1975.

2. Knowles, M.S. The Modern Practice of Adult Education: From Pedagogy to Andragogy, 2nd ed. Cambridge Books, New York, 1980.

3. Samuel, O.W. Towards a Curriculum of General Practice Training, Occasional Paper 44. Royal College of General Practitioners, London, 1990.

4. Lewis, A.P. \& Bolden, K.J. General practitioners and their learning styles. $J \boldsymbol{R}$ Coll Pract 1989, 39: 187-189.

5. Grant, J., Marsden, P. \& King, R.C. Senior house officers and their training. Br Med J 1989, 299: 1263-1268.

6. Hoffbrand, B.I. Away with the system review - a plea for parsimony. Br Med J 1989, 298: 817-819.

7. Edwards, P.H., O'Toole, O.B. \& Pharoah, C. Survey of young principal groups in the United Kingdom. J R Coll Gen Pract 1988, 38: 61-63.

8. Koppel, J.I. \& Pietroni, R.G. Higher Professional Education Courses in the United Kingdom Occasional Paper 51. Royal College of General Practitioners, London, 1991.
9. What Sort of Doctor? Assessing Quality of Care in General Practice. Report from General Practice 23. Royal College of Practitioners, London, 1985.

10. Standing Committee for Postgraduate Medical Education. Medical Audit: The Educational Implications the 'SCOPME' Report. The Standing Committee for Postgraduate Medical Education, London, 1989.

11. Balint, M. The Doctor, His Patient and the Illness. Pitman Medical Publishing, London, 1957.

12. Pettitt, G.A. The Nelson Balint group: evolution of one possible method for continuing postgraduate education and constructive peer-review in small centres. $N Z$ Med J 1981, 93: 45-46.

13. Nicholls, K. \& Jenkinson, J. Leading a Support Group. Chapman \& Hall, London, 1991. 